\title{
Company Value, Real Options and Financial Leverage
}

O. Drahovzal

This paper deals with determining of the value of companies and financial leverage. The author tries to find the optimum debt ratio for selected companies in the Czech Republic. The method of yield option extension is used for evaluating a company. The DCFC method was selected as the yield method, due to its simplicity. The dynamic model used allows us to make changes in the debt ratio with recalculations of all parameters that depend on it. The assessment is made from two points of view: Firstly, the maximum of the total amount of financial resources, and, secondly, the maximum of the inverse sums of the ROE index and the ratio of equity to the value of the company. The values of the total debt ratio and the long-term debt ratio are shown as results.

Keywords: evaluation, real options, financial leverage.

\section{Company value}

The value of a company, whose stocks are traded, can be determined from its present market value. When there is no trading, plenty of methods exist, which can be split into six groups: balance sheet, income statement, mixed methods (goodwill), cash flow discounting, value creation, and options. A method that assesses the value of the assets with a forecast of future incomes of the company and recalculating it to the present value was chosen for future evaluation.

\subsection{Evaluation by the DFCF method}

In the Discounted Free Cash Flow method, the value of a company is defined as the sum of the discounted free cash flows for the next five years, and the perpetuity of the free cash flow in the sixth year. Free cash flow is given by the following equation:

$$
F C F=E B I T \cdot(1-t)+A D-I N V,
$$

where $E B I T$ is earnings before interest and taxes, $t$ is tax rate, $A D$ is the amount of amortization and depreciation, and $I N V$ is the value of the investments. The value of the company is calculated with the following formula, which uses a six-year prediction. Five years are estimated separately and the sixth is used for perpetuity calculation. This structure was used because of the difficulties in making predictions over a longer period of time. The formula for company value calculation is:

$V=\sum_{t=1}^{5} \frac{F C F_{t}}{(1+W A C C)^{t}}+\frac{F C F_{6}}{(W A C C-g) \cdot(1+W A C C)^{5}}$,

where $F C F$ is the free cash flow for the given year, $g$ is the expected growth rate of future cash flows, and WACC is the weighted average cost of capital:

$$
W A C C=r_{e} \frac{E}{D+E}+r_{d}(1-t) \frac{D}{D+E},
$$

where $r_{e}, r_{d}$ are the relative costs of equity and debt, $E, D$ are the amounts of equity and debt, and $t$ is the tax rate - the cost of the debt is lowered by the tax shield.

\subsection{Evaluation by real options}

This method of evaluation uses the option extension of the yield method. The value of a company can be assessed as the call option on company assets with the strike price equal to the value of the debt. The Black - Scholes formula for the call option is:

$$
\begin{aligned}
& C=S \cdot N\left(d_{1}\right)-X \cdot e^{-r t} \cdot N\left(d_{2}\right), \\
& d_{1}=\frac{\ln \left(\frac{S}{X}\right)+\left(r+\frac{\sigma^{2}}{2}\right) \cdot t}{\sigma \cdot \sqrt{t}}, \\
& d_{2}=d_{1}-\sigma \cdot \sqrt{t},
\end{aligned}
$$

where $S$ is the current price of the asset, $X$ is the strike price of the asset, $r$ is the risk-free interest rate, $t$ is time to expiration of the option, $N()$ is the standard normal cumulative distribution function and $\sigma$ is the volatility of the price of the asset. The formula for calculating the value of the company then has the following shape:

$$
V=A \cdot N\left(d_{1}\right)-D e^{-r t} \cdot N\left(d_{2}\right),
$$

where $A$ is the value of the company's assets (determined by the DFCF method), $D$ is the value of the debt, and $t$ is the time of the debt's maturity. The other parameters have the same meaning as in the standard call option. The value of volatility $\sigma$ can be determined directly from the company's stock history, or can be specified by the following formula:

$\sigma=\sqrt{\left(1-P_{D}\right)^{2} \cdot \sigma_{A}^{2}+P_{D}^{2} \cdot \sigma_{0}^{2}+2 P_{D} \cdot\left(1-P_{D}\right) \cdot \sigma_{A} \cdot \sigma_{0} \cdot \rho}$,

where $\sigma_{A}, \sigma_{0}$ are the standard deviations of the prices of shares and obligations, $\rho$ is the correlation coefficient between them, and $P_{D}$ is the ratio of debt to total capital.

Option values calculated by binomial and trinomial tree methods were also used to form a basis for comparison. All three results are very similar. The only slight difference is when the option value approaches zero. The value calculated by the binomial tree is the fastest method in converging to zero, and the Black - Scholes formula is the slowest.

\section{Financial leverage}

As the company debt increases, the equity decreases, as it is replaced by the debt (the same total amount of liabilities and equity is assumed). It is generally true that outside capital is less expensive than own capital. So with the presumption of maintaining the same profit as the company had had before the change in its capital structure, the cost-effectiveness of the equity (the profit divided by the equity) logically increases. If the original cost-effectiveness is high enough for the company 


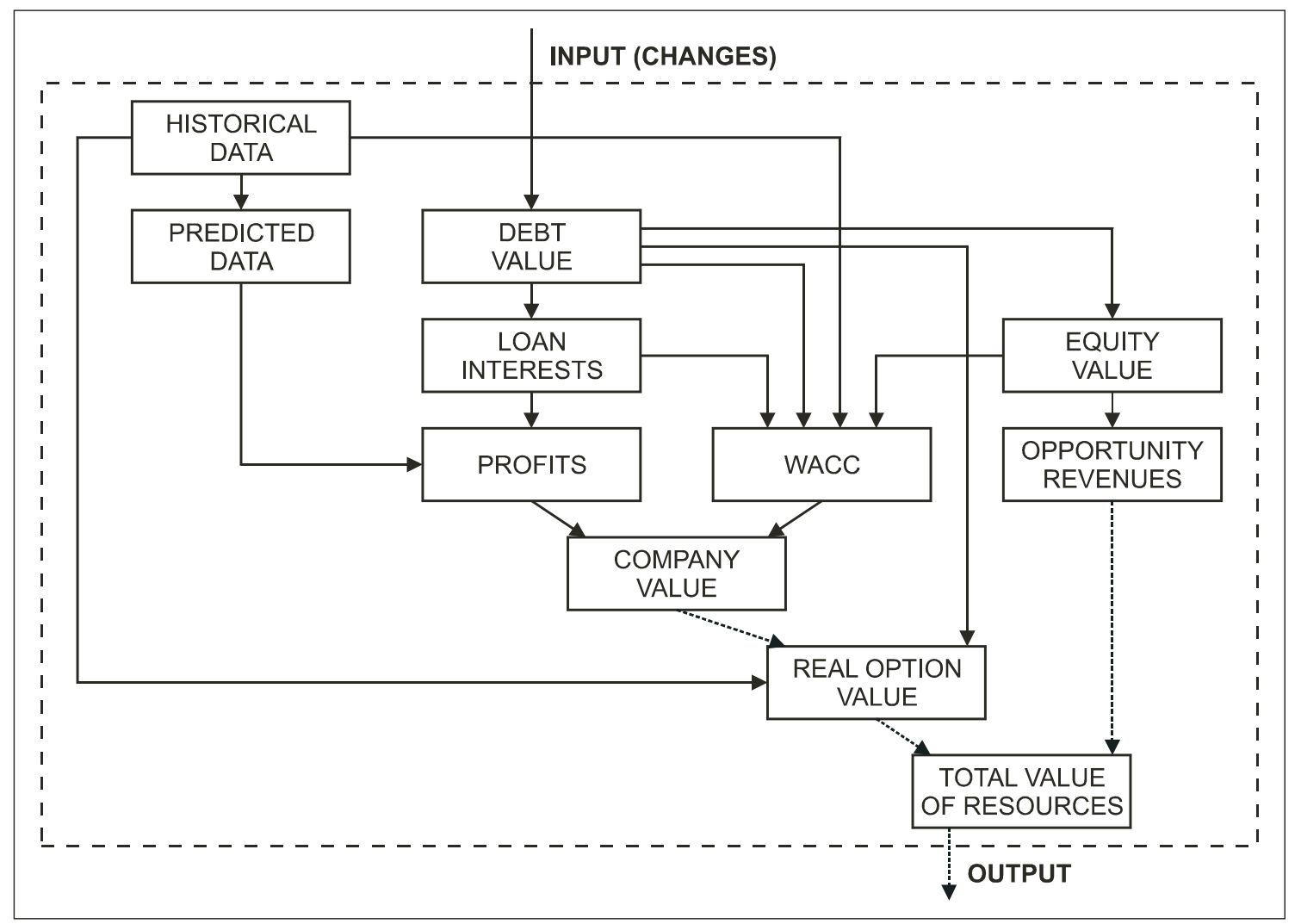

Fig. 1: Structure of the calculation model

owner, the profit can be lowered by reducing prices, which can result in increased competitiveness in the market. The debt volume cannot of course be increased to infinity.

\section{Calculation model}

Because the parameters used for company valuation by the DFCF method vary during changes of debt value, a dynamic model had to be used. It recalculates all values - loan interests, WACC and even the values of predicted profits within the years (interest and tax shields influence the value of profit). The final value of a company and the value of the debt are used as input for the real option. The amount of equity and the value of the ROE index (profitability of the equity) are recalculated, also depending on the debt ratio. For completeness, the range of long-term debt ratio is counted from $0 \%$ to $100 \%$. The total amount of resources is the sum of the value of the option and the opportunity income of capital not embedded in the equity of the company.

\section{Solution and results}

The following companies were selected for evaluation: Pražská energetika, a.s. (PRE), Skupina ČEZ, a.s. (CEZ), Pražská plynárenská, a.s. (PPAS), Pražská teplárenská, a.s. (PTAS), Severočeské doly, a.s. (SDAS), and České aerolinie, a.s. (CSA).

For each company, the amount of own capital costs, the actual level of debt ratio, interest and other entries were found in public annual reports downloaded from the Internet in the first step. In the second step, the volatility of assets for each company in the list was calculated from the four-year daily history of stock prices. In the third step, free cash flows for the next six years were roughly predicted by estimating the profit, amortization and depreciation and investment value. The estimates were made by processing the six-year history. Regression functions (polynomic, logarithmic or exponentional) or some coefficients and ratios (e.g. ratio of investments and depreciations) resulted from the estimates and were used for the prediction. Because of the simplification, the expected growth rate of the future cash flow $g$ was estimated at the same value for each company. For determining the optimum debt ratio, two evaluation methods were used. The first uses the maximum of the total amount of financial resources, while the second uses the maximum of the inverse sums of the $R O E$ index and the ratio of equity to the company's value. This index evaluates the debt ratio also from the point of view of the profitability of the equity. The formula for the optimum debt ratio from the view of total value of resources is:

$D_{V}=\max \left\{V_{D R}+O R_{D R} ; 0 \leq D R \leq 1\right\}$

where $D R$ is the debt ratio, $V$ is the option value and $O R$ is the opportunity revenues. The formula for the optimum debt ratio for profitability is:

$D_{V}=\max \left\{-\left(\frac{E_{D R}}{V_{D R}}+R O E_{D R}\right) ; 0 \leq D R \leq 1\right\}$

where $D R$ is the debt ratio, $E$ is the value of the equity, $V$ is the value of the option and $R O E$ is the profitability of the equity.

The long-term debt ratio (ratio of the long-term loans to the sum of the long-term loans and the equity) is presented as 


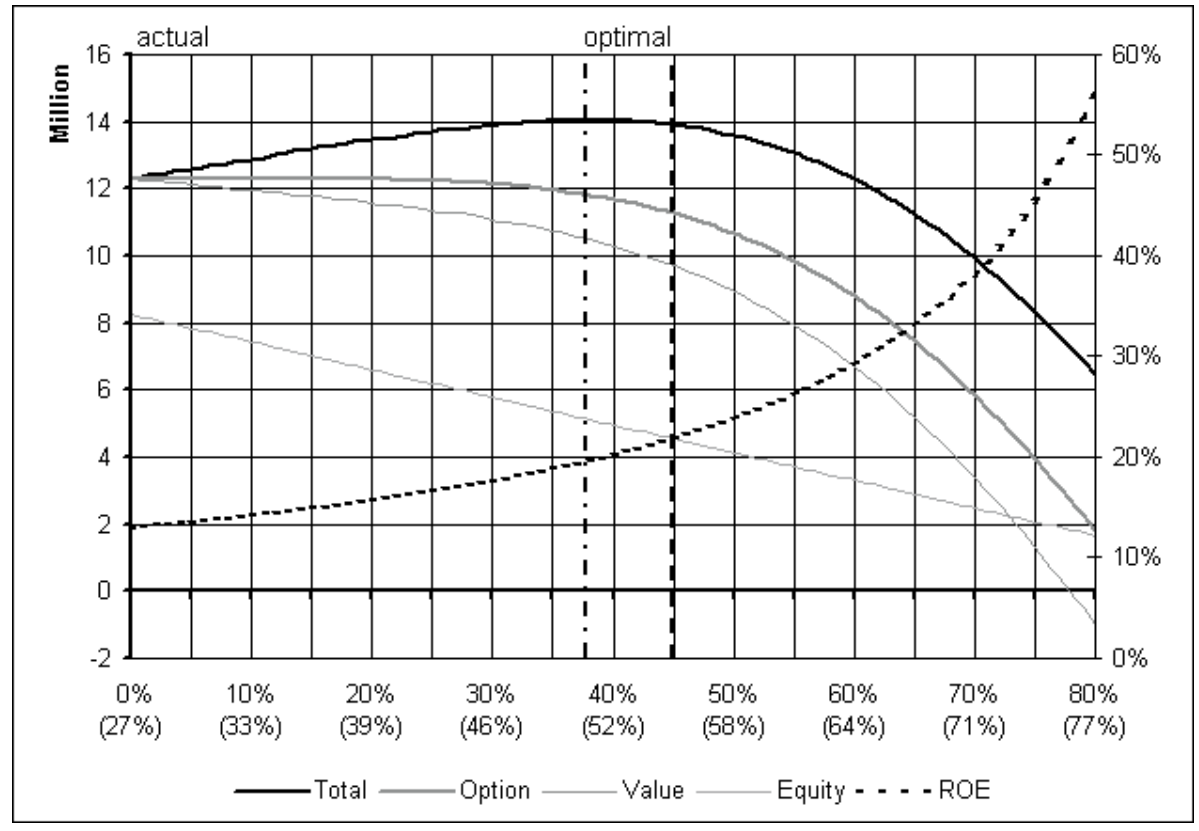

Fig. 2: Sample of the resultant graph for company PRE

the main result. The total debt ratio is shown in parenthesis (the ratio of the outside capital to the total amount of capital).

Table 1: Results of calculations

\begin{tabular}{|c|c|c|c|}
\hline Debt ratio & Actual & Optimum $(V)$ & Optimum $(E)$ \\
\hline PRE & $0 \%(27 \%)$ & $36 \%(49 \%)$ & $44 \%(54 \%)$ \\
\hline CEZ & $6 \%(36 \%)$ & $32 \%(53 \%)$ & $40 \%(59 \%)$ \\
\hline PPAS & $0 \%(57 \%)$ & $34 \%(71 \%)$ & $45 \%(76 \%)$ \\
\hline PTAS & $33 \%(40 \%)$ & $34 \%(41 \%)$ & $47 \%(53 \%)$ \\
\hline SDAS & $0 \%(26 \%)$ & $32 \%(50 \%)$ & $37 \%(53 \%)$ \\
\hline CSA & $34 \%(57 \%)$ & $35 \%(57 \%)$ & $56 \%(63 \%)$ \\
\hline
\end{tabular}

\section{Conclusion}

The calculations show that the energy companies in the Czech Republic, with a few exceptions, are using a very low level of outside capital. The managers are not even lowering their profitability indices, but they are also failing to increase the yield from the equity to a level which could be achieved with a better capital structure in the companies.

\section{Acknowledgments}

This research was financially supported by Research Project MSM6840770017 of the Czech Ministry of Education, Youth and Sports.

\section{References:}

[1] Scholleová, H.: "Real options." Dissertation thesis, Prague, 2004.

[2] Sedláček, J.: Accounting Data in Manager's Hand. Prague: Computer Press 2001.

[3] Fernández, P.: Valuation Methods and Shareholder Value Creation. San Diego: Academic Press 2002.

[4] So̊vová, H.: Financial Analysis. Prague: Bank Institut 2000.

[5] Annual Reports and Stock Price Histories of the Investigated Companies.

Ing. Ota Drahovzal drahovo@fel.cvut.cz

Department of Economics, Management and Humanities

Czech Technical University in Prague

Faculty of Electrical Engineering

Technická 2

16627 Prague 6, Czech Republic 